\title{
Neuroendocrine evaluation of 5-HT1A function in male alcoholic patients
}

\author{
E. Pinto ${ }^{a,}$, J. Reggersa, W. Pitchota, M. Hansenne ${ }^{a}$, S. Fuchs ${ }^{a}$, M. Ansseau ${ }^{a}$ \\ aUniversity of Liège, Department of Psychiatry, CHU du Sart Tilman (B35), B-4000 Liège, Belgium
}

KEYWORDS: alcoholism; flesinoxan; serotonin; 5-HT1; prolactin; cortisol

\section{ABSTRACT}

Background: Preclinical evidences support the hypothesis of a serotonergic dysfunction in alcohol preference. In human, studies have demonstrated a serotonergic hypoactivity in alcoholism. However, little is known about the role of 5-HT1A receptors.

Methods: We assessed the hormonal (prolactin and cortisol) responses to flesinoxan (a highly potent and selective 5-HT1A agonist) in 12 male inpatients meeting DSM-IV criteria for alcohol dependence, 3 weeks after the last reported use of alcohol and antidepressants. These patients were compared to 10 male controls.

Results: There was a highly significant difference between alcoholic patients and controls for the area under the curve relative (AUCr) values of prolactin responses. AUCr values of cortisol responses to flesinoxan showed a trend towards lower values in alcoholics compared to controls.

Conclusion: These results support the implication of the serotonergic system, and particularly a decreased sensitivity of post-synaptic 5-HT1A receptors, in alcoholism. 


\section{Introduction}

Several preclinical evidences support the hypothesis of biological vulnerabilities in the pathogenesis of alcohol dependence. Serotonin (5-hydroxytriptamine, 5-HT), as well as many other neurotransmitters, is thought to play a major role in pathologic drinking (Koob and Roberts, 1999). In animal as well as in human studies, important advances have been made in clarifying the role of 5-HT as a central mediator of alcohol consumption, suggesting an impaired 5-HT activity in alcohol preference. Furthermore, many studies have also highlighted the possible modulation of behavioral components in some alcoholic patients by brain 5-HT (Pettinati et al., 2000).

As for the specific involvement of 5-HT1A receptors in alcohol dependence, few data are available. Animal studies have shown to be controversial. A selective reduction in alcohol intake and dopamine release was indeed observed in alcohol-drinking rats treated with the partial 5HT1A agonist ipsapirone (Yoshimoto and McBride, 1992), or the 5-HT1A agonist 8-OH-DPAT (Schreiber et al., 1993). Furthermore, the administration of the presynaptic autoreceptor acting 5-HT1A antagonist WAY-100635, which increases 5-HT neurotransmission, was shown to reduce alcohol consumption in rodents (Zhou et al., 1998). Yet, another study using 8-OH-DPAT injections specifically in the median or dorsal raphe nucleus showed an enhanced alcohol intake (Tomkins et al., 1994). In humans, post-mortem studies have shown a reduction in the expression of the 5-HT1A receptors in brains of alcohol-dependent deceased patients (Dillon et al., 1991). Pharmacological evidence also supports the implication of a low 5-HT1A activity in alcoholism. In non human primates as well as in men, the partial 5-HT1A agonist buspirone seemed to decrease alcohol intake. However, buspirone may be efficient only when alcoholism is associated with anxiety (Tollefson et al., 1990).

In order to assess the specific implication of 5-HT1A receptors in alcohol preference, we performed a preliminary study in a small group of alcoholic patients, using the prolactin (PRL) and the cortisol responses to flesinoxan challenge test. Flesinoxan is a highly potent and selective 5-HT1A agonist that was shown to induce a significant and dose-dependant increase in PRL and cortisol in healthy volunteers (Pitchot et al., 1995; Seletti et al., 1995).

\section{Methods and materials}

\section{SUBJECTS}

The study was carried out in 12 male inpatients (mean age 47.1 years; S.D. $=10$ ) hospitalized in the Department of Psychiatry of the University Hospital of Liège (Belgium) for alcohol detoxification. They all met DSM-IV criteria for alcohol-dependence, the mean age of onset of alcohol-dependence being 27.0 years (S.D. $=7.4$ ). No history of suicide was recorded. Patients scored less than 7 on the 17-item Hamilton depression scale and were all medication-free at the time of the study, three weeks after the last reported use of alcohol or antidepressants. The washout was supervised during their hospitalization. Subjects were compared to 10 male controls, comparable for age (mean age 43.8 years; S.D. $=7.6$ ) and weight $(72.9 \mathrm{~kg}$; S.D. $=8.5 \mathrm{in}$ 
the alcohol group, $73.5 \mathrm{~kg}$; S.D. $=8.6$ in the control group) recruited among the staff of the University Hospital of Liège, who all underwent a medical interview to exclude psychiatric or somatic disorders. Moreover, none had a family history of alcohol-dependence.

\section{NEUROENDOCRINE PROCEDURE}

The flesinoxan challenge test was performed at $0830 \mathrm{~h}$ after an overnight fast in the Department of Psychiatry of the Liège University Hospital. Flesinoxan (1 mg/70 kg of body weight), diluted in saline solution to obtain $20 \mathrm{ml}$, was injected IV in $10 \mathrm{~min}$, and blood samples of $10 \mathrm{ml}$ were collected $30 \mathrm{~min}$ and immediately before the injection, and 15, 30, 60, 90 and $120 \mathrm{~min}$ after the injection. Prolactin and cortisol were measured by radioimmunoassay (RIA) with intra-assay and inter-assay coefficients of variation of 10.0 and $10.0 \%$ for PRL (detection limit $=10 \mu / \mathrm{l}$ ) and 4.3 and $8.3 \%$ for cortisol (detection limit $=5 \mu \mathrm{g} / \mathrm{l}$ ) (Ansseau et al., 1984). Hormonal responses following flesinoxan were assessed by the relative value of the area under the curve (AUCr) between the injection and the last blood sample. Calculation is based upon geometrical methods, and the relative value is obtained after the subtraction of baseline value from the AUC. This avoids any baseline effect on hormonal response values.

\section{STATISTICAL ANALYSES}

Statistical analyses were performed using Statistica for Windows, Version 5.1 (Statsoft, Tulsa, OK, 1996). A simple ANOVA was performed to compare the AUCr for prolactin and cortisol responses between alcoholics and controls. Data were also analyzed by a 2 (group) by 6 (time) mixed ANOVA design with time as the repeated measure, while post hoc comparisons were made with the Tukey's honestly significant difference (HSD) test (Spjotvoll - Stoline modification for unequal $n \mathrm{~s}$ ).

\section{Results}

There was a highly significant difference $\left(F_{1,20}=8.58, \mathrm{p}>0.008\right)$ between alcoholic patients and controls for the area under the curve relative values of prolactin responses (Fig. 1): $5232 \mu \mathrm{IU}$ $\mathrm{min} / \mathrm{l}(\mathrm{SD}=7734)$ vs $16233 \mu \mathrm{IU} \mathrm{min} / \mathrm{l}(\mathrm{SD}=9892)$ whereas no difference was found in PRL levels at baseline between alcoholics and controls $(139.7 \mu \mathrm{IU}, \mathrm{SD}=53.42$ vs $146.4 \mu \mathrm{IU}, \mathrm{SD}=$ 76.83). Furthermore, repeated measures analysis of PRL responses to flesinoxan showed a significant effect for group $(F[1,20]=5.42, p<.03)$, a highly significant effect for time $(F[5,100]$ $=16.1, p<.001)$ and a group-by-time interaction $(F[5,100]=2.9, \mathrm{p}<.01)$. Fig. 1 shows the comprehensive profile of PRL response to flesinoxan as well as post hoc differences at each time.

Cortisol at baseline was not statistically different in the two groups $(121.7 \mu \mathrm{g}, \mathrm{SD}=43.5 \mathrm{in}$ alcoholics vs $114.6 \mu \mathrm{g}, \mathrm{SD}=38.25$ in controls), but AUCr values of cortisol responses to flesinoxan were lower in alcoholics compared to controls (Fig. 2), only at a trend level $\left(F_{1,20}=\right.$ 3.99, p < 0.059): minus $1478 \mu \mathrm{g} \mathrm{min/l} \mathrm{(SD} \mathrm{=} \mathrm{2927)} \mathrm{vs} 2424 \mu \mathrm{g} \mathrm{min} / \mathrm{l}(\mathrm{SD}=5973)$. Repeated measures analysis of cortisol responses to flesinoxan showed no significant effect for group nor for time but there was a highly significant group-by-time interaction $(F[5,100]=3.36, \mathrm{p}<.008)$. 
Fig. 2 shows the comprehensive profile of cortisol response to flesinoxan. No significant differences were found in post hoc comparisons.

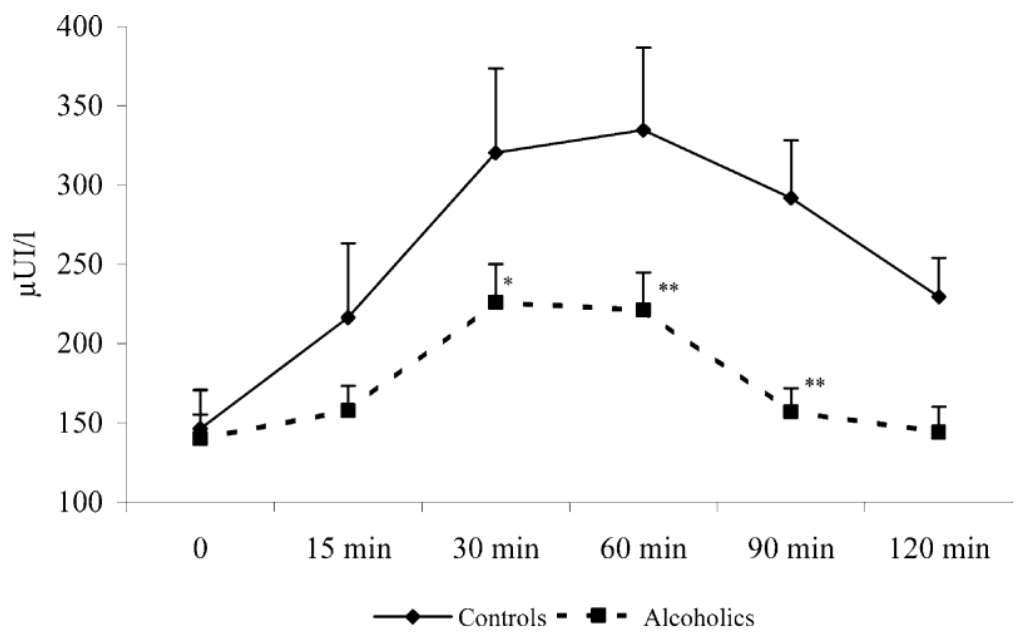

Fig. 1. Prolactin response to flesinoxan among Alcoholics $(N=12)$ and Controls $(N=10)$. Post Hoc Tukey HSD comparisons : $* p<.05 ; * * p<.01$. Bars indicate Standard Error of Means (SEM).

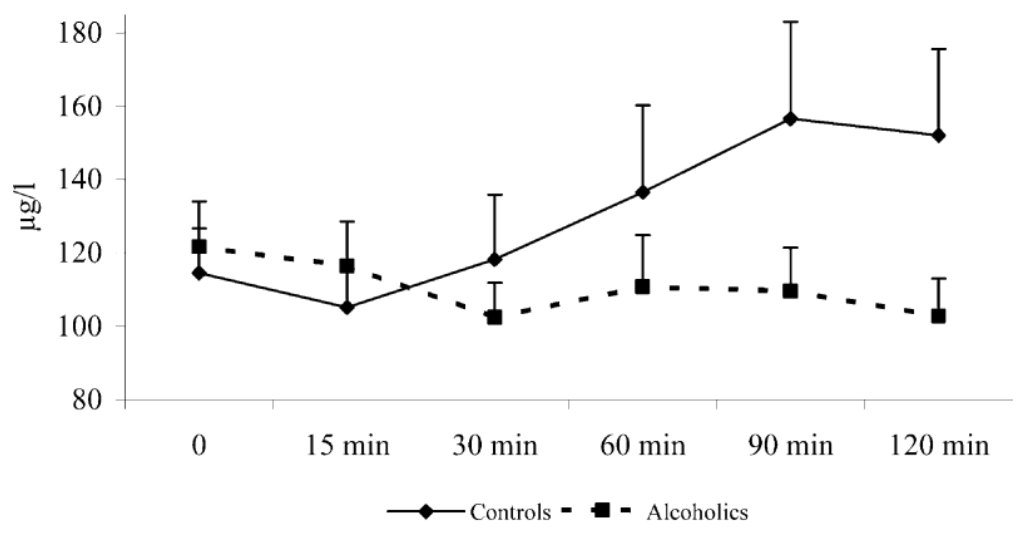

Fig. 2. Cortisol response to flesinoxan among Alcoholics $(N=12)$ and Controls $(N=10)$. Post Hoc Tukey HSD comparisons : $* p<.05 ; * * p<.01$. Bars indicate Standard Error of Means (SEM).

\section{Discussion}

This study confirmed the possible implication of 5-HT1A receptors in alcoholism, and the usefulness of the flesinoxan challenge test in investigating 5-HT1A activity in non-depressed alcoholic patients. The discrepancy between PRL and cortisol responses to flesinoxan may be linked to the possible activation of cortisol secretion through other 5-HT receptors such as 5HT2 receptors while PRL secretion seems to be mainly dependant on 5-HT1A post-synaptic receptors (Lee et al., 1991; Pitchot et al., 1995). Until now, few flesinoxan human studies were available in psychiatric pathology, most of them concerning depressive disorders, personality or 
behavioral characteristics (Pitchot et al., 1995; Hansenne et al., 1997; 2000; 2001). Since our results are not influenced by the depressive status of the patients, it can be hypothesized that this neuroendocrine challenge test will be of much interest in future investigations about alcoholism. As for the main result of this study, larger samples will be needed to confirm the role of 5-HT1A receptors in alcoholism. In particular, since this disorder is often associated with impulsiveness and/or aggression (especially in type II alcoholics according to Cloninger's typology), a distinction between type I and type II patients should be made in further studies using the flesinoxan challenge test. Blunted neuroendocrine responses to 5-HT1A agonist ipsapirone have indeed been shown to be correlated with aggression in aggressive populations and PRL responses to buspirone showed to be lower in violent compared to non-violent parolees. These results were recently replicated by Cleare and Bond who found an inverse correlation between 5-HT1A receptor function and aggression (Cleare and Bond, 2000). Moreover, lower PRL response to flesinoxan has been reported among patients with borderline personality disorder (BPD) with history of suicide attempt compared to BPD patients without history of suicide attempt. The implication of an hypo-5-HT functioning in the impulsivityalcoholism spectrum tends to be as well illustrated through various studies about suicide in alcoholic patients. Low levels of 5-HT and/or 5-HIAA were found in blood and CSF of alcoholic subjects who attempted suicide, and it was recently shown that the risk for high lethality suicidal behavior was partly dependent on 5-HTT promoter gene polymorphisms (Gorwood et al., 2000). On the other hand, abnormalities in 5-HT1A receptors may underlie suicidal behavior in depressed patients (Pitchot et al., 1995). Thus, measuring aggressiveness and more generally impulsivity while performing the flesinoxan challenge may contribute to illustrate the specific implication of 5-HT1A receptors in such aspects of alcoholism.

Finally, another question rises when observing the blunted responses to flesinoxan compared to controls in our sample : is the observed dysfunction of 5-HT1A receptors in our alcoholic patients linked to some extend to alcohol craving ? In the last decade, many findings have indeed suggested that serotonin may play a role in craving for alcohol (Ciccocioppo, 1999). Based upon pharmacological studies showing some effectiveness in reducing alcohol consumption with serotonergic agents, it has been hypothesized that the mood-regulating effects of SSRIs are responsible for decreasing the need for relief of negative affect and thus craving for alcohol (Cornelius et al., 1997). Given the acute and chronic effects of alcohol on 5-HT levels, another possibility to explain the relationship between 5-HT and craving could be that individuals with constitutionally low serotonin function, as it has been widely observed in chronic alcoholic patients, drink to increase serotonergic activity and "self-medicate" themselves against mood dysregulation. Anton has suggested that the link between craving and 5-HT abnormalities may lie in the obsessional thinking about alcohol consumption experienced by chronic alcoholics (Anton, 1996). Converging observations showing a serotonergic dysfunction in obsessivecompulsive disorder (OCD) and a specific efficacy of serotonergic agents in OCD on one hand (Goodman et al., 1990), and similar neuroanatomical findings in both OCD and alcohol dependence on the other hand (Anton, 2000), led to the conclusion that a direct link may exist between 5-HT and craving. Because they rise many research opportunities, our results may then be a first step in the better understanding of the specific relationship between serotonin, and in particular its 5-HT1A receptors, and alcoholism. 


\section{References}

Ansseau, M., Scheyvarts, M., Doumont, A., Poirrier, R., Legros, J.J., Franck, G., 1984. Concurrent use of REM latency, dexamethasone suppression, clonidine and apomorphine tests as biological markers of endogenous depression. Psychiatry Res., 261-272.

Anton, R.F., 1996. Neurobehavioral basis for the pharmacotherapy of alcoholism: current and future directions. Alcohol Alcohol 31 (S1), 43-53.

Anton, R.F., 2000. Obsessive-compulsive aspects of craving: development of the Obsessive Compulsive Drinking Scale. Addiction 2, 211-217.

Ciccocioppo, R., 1999. The role of serotonin in craving from basic research to human studies. Alcohol Alcohol 2, 244-253.

Cleare, A.J., Bond, A.J., 2000. Ipsapirone challenge in agressive men shows an inverse correlation between 5-HT1A receptor function and aggression. Psychopharmacology 148, 344-349.

Cornelius, J.R., Salloum, I.M., Ehller, J.G., Jarrett, P.J., Cornelius, M.D., Perel, J.M., Thase, M.E., Black, A., 1997. Fluoxetine in depressed alcoholics: a double-blind, placebo-controlled trial. Arch. Gen. Psychiatry 54, 700705.

Dillon, K.A., GrossIsseroff, R., Israeli, M., Biegeon, A., 1991. Autoradiographic analysis of serotonin 5HT1A receptor binding in the human brain post-mortem effect of age and alcohol. Brain Res. 554, 56-64.

Goodman, W.K., Price, L.H., Delgado, P.L., Palumbo, J., Krystal, J.H., Nagy, L.M., Rasmussen, S.A., Heninger, G.R., Charney, D.S., 1990. Specificity of serotonin reuptake inhibitors in the treatment of obsessivecompulsive disorders. Arch. Gen. Psychiatry 47, 577-585.

Gorwood, P., Batel, P., Ads, J., Hamon, M., Boni, C., 2000. Seronin transporter gene polymorphisms, alcoholism, and suicidal behavior. Biol. Psychiatry 48, 259-264.

Hansenne, M., Pitchot, W., and Ansseau, M., 2001, Serotonin, personality and borderline personality disorder. Acta Neuropsychiatrica in press.

Hansenne, M., Pitchot, W., Gonzalez Moreno, A., Machurot, P.Y., Reggers, J., Ansseau, M., 1997. The harm avoidance dimension of tridimensional personality questionnaire and 5-HT1A activity in depression. Biol Psychiatry 42, 959-961.

Hansenne, M., Pitchot, W., Pinto, E., Papart, P., Ansseau, M., 2000. Seronergic-1a activity and contingent negative variation. Biol. Psychology 52, 259-265.

Koob, G.F., Roberts, A., 1999. Brain reward circuits in alcoholism. CNS Spectrums 4, 23-37.

Lee, M.A., Nash, J.F., Barnes, M., Meltzer, H.Y., 1991. Inhibitory effect of ritanserin on the 5-hydroxytryptophan-mediated cortisol ACTH and prolactin secretion in humans. Psychopharmacology 103, 258264.

Pettinati, H.M., Oslin, D., Decker, K., 2000. Role of serotonin and selective-serotonin pharmacotherapy in alcohol dependance. CNS Spectrums 2, 33-46.

Pitchot, W., Ansseau, M., Gonzalez Moreno, A., Lembreghts, M., Hansenne, M., Wauthy, J., Reel, C., Jammaer, R., Papart, P., Sulon, J., Legros, J.J., 1995. The flesinoxan 5-HT1A receptor challenge in major depression and suicidal behaviour. Pharmacopsychiatry 28 (Suppl.), 91-92.

Schreiber, R., Opitz, K., Glaser, T., De Vry, J., 1993. Ipsapirone and 8-OH-DPAT reduce ethanol preference in rats: involvement of presynaptic 5-HT1A receptors. Psychopharmacology 112, 100-110. 
Seletti, B., Benkelfat, C., Blier, P., Annable, B., Gilbert, F., de Montigny, C., 1995. Serotonin 1A receptor activation by flesinoxan in humans. Body temperature and neuroendocrine responses. Neuropsychopharmacology 13, 93-104.

Tollefson, G.D., Monague-Clouse, J., Lancaster, S.P., 1990. Buspirone in comorbid alcohol dependency and generalized anxiety disorders. Ther Bull 1, 35-50.

Tomkins, D., Sellers, E., Fletcher, P., 1994. Median and dorsal raphe injections of the 5-HT1A agonist 8-OHDPAT and the GABA-A agonist muscinol increase voluntary ethanol intake in Wistar rats. Neuropharmacology 33, 349-358.

Yoshimoto, K., McBride, W.J., 1992. Regulation of nucleus accumbens dopamine release by the dorsal raphe nucleus in the rat. Neurochem Res 17, 401-407.

Zhou, F.C., McKinzie, D.L., Patel, T.D., Lumeng, L., Li, T.K., 1998. Additive reduction of alcohol drinking by 5 HT-sub(1A) antagonist WAY-100635 and serotonin uptake blocker fluoxetine in alcohol-preferring P rats. Alcohol Clin. Exp. Res. 22, 266-269. 